\section{Analysis of Bitcoin's Impact on the Efficiency of a Diversified Portfolio for Brazilian Investors}

Davi Trindade Batista ${ }^{1}$

Carlos F. Alves ${ }^{2}$ (iD

\section{Abstract}

Purpose - This paper aims to investigate if the inclusion of Bitcoin among the assets available to retail investors in the Brazilian market has an impact on the efficient frontier and, therefore, on the optimal choices of investors.

Design/methodology/approach - This study calculates the efficient frontier with and without the inclusion of Bitcoin and estimates optimal portfolios for different criteria and time intervals. The sample period runs from 07/01/2013 to $06 / 30 / 2018$ and the daily closing values of the selected assets/indices were used.

Findings - This study finds evidence that the inclusion of Bitcoin among the investment alternatives would cause a statistically significant positive displacement and an expansion of the efficient frontier of the Brazilian retail market. This would result in a significant increase in the return on the tangency portfolio. In addition to improving the indicators of optimization of the risk-return binomial, the cryptoasset would be included in many optimal portfolios in the 2013Q32018Q2 period.

Originality/value - The results obtained show that, as reported for more developed markets, Bitcoin has caused an expansion of the efficient frontier of the Brazilian retail market.

Keywords - Bitcoin; Cryptocurrency; Portfolio Selection; Asset Allocation; Brazilian Capital Market.

1. Securities and Exchange Commission of Brazil, Office of Investor Protection and Assistance, Sao Paulo, Brazil

2. University of Porto and CEF.UP, Faculty of Economics, Porto, Portugal

How to cite:

Batista, D., Alves, C., (2021). Analysis of Bitcoin's Impact on the Efficiency of a Diversified Portfolio for Brazilian Investors. Revista Brasileira de Gestão de Negócios, 23(2), firstpage-lastpage.
Received on:

08/12/2019

Approved on:

$10 / 01 / 2020$

Responsible Editor:

Prof. Dr. Joelson Sampaio

\section{Evaluation process:}

Double Blind Review

\section{Reviewers:}

Vinicius Brunassi. One of the reviewers decided not to disclose his/ her identity.

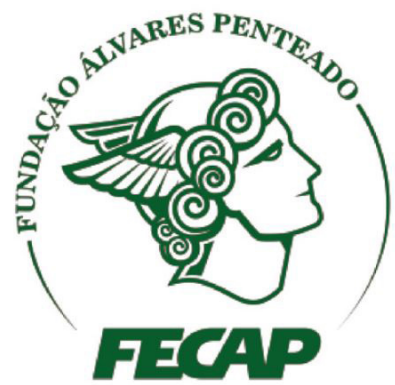

Revista Brasileira de Gestáo de Negócios

https://doi.org/10.7819/rbgn.v23i2.4098 


\section{Introduction}

In the last decade, Bitcoin was certainly the (new) asset that most attracted the media and part of the scientific community, and recently that interest has reached nonspecialist audiences. However, although there is already some investigation, many questions about that cryptoasset still need to be answered. Among them, whether Bitcoin would increase the efficiency of a diversified portfolio in the local and global financial markets. Therefore, this article aims to answer the following question: is Bitcoin investment capable of increasing the efficiency of a diversified portfolio of retail investors in the Brazilian market?

There are several studies on the impact of Bitcoin on the efficiency of the investment portfolio in some of the leading international markets (see, for example, for the United States, Brière, Oosterlinck, \& Szafarz, 2015; Wu \& Pandey, 2014) and studies on the impact of the inclusion of specific assets and indices in the investment portfolio of the Brazilian market (Caldeira, Moura, Santos, \& Tessari, 2014; Cunha \& Samanez, 2014; Lopes \& Furtado, 2006; Oliveira \& Silva, 2009; Silveira \& Barros, 2010). However, studies that address Bitcoin's potential influence in a diversified portfolio of assets within Brazilian investors' reach are unknown, so the present study contributes to the finance literature.

The study results are potentially interesting due to the Brazilian market's structural difference compared to those of more developed countries, emphasizing the United States. While these are deep capital markets with sophisticated investors and have lived with low-interest rates, Brazil still lives with high real and nominal interest rates and has a poorly developed capital market. Another significant difference between Brazil and most developed countries concerns economic freedom: Brazil occupies the $153^{\text {rd }}$ position in a ranking of 180 countries, having been placed in the mostly unfree category and with scores alarmingly close to that of the the worst category (repressed category), which is a country that "represses economic freedom" (Heritage Foundation, 2018). According to the Organization for Economic Cooperation and Development (OECD), Brazil's financial literacy level is low (Organization for Economic Cooperation and Development, 2015). This OECD survey indicates that even the country's new generation will have difficulty understanding cryptoassets like Bitcoin.

However, it is noteworthy that although the present study focuses on Brazil, its conclusions are relevant to other countries, given that there is evidence that investors use Bitcoin as an alternative for investing their money in multiple small and emerging markets. That is the case of Cyprus (Farrell, 2013), Greece (Rosenfeld, 2015), Argentina (Popper, 2015), India (Kashyap, 2016), China (Wildau, 2017), Zimbabwe (Urban, 2017), Venezuela (Voge, 2018) and Turkey (Cuen, 2018).

It should also be borne in mind that, even for more developed markets, the literature focuses on the initial phase of Bitcoin (2010-2013) (e.g., Brière, Oosterlinck, \& Szafarz, 2015; Wu \& Pandey, 2014), while this article encompasses the following period, during which Bitcoin was consolidated and reached a broader audience, thus being a complementary contribution to studies carried out outside Brazil.

This study is also relevant in terms of regulation and supervision of the capital market, since, although Bitcoin is outside the competence of the Securities and Exchange Commission of Brazil (SEC) because it is not a security, it is the responsibility of this authority to adjust the regulation of the Brazilian capital market according to its evolution and disseminate financial education to the population. It should be pointed out that there are already more than one million investors registered on Bitcoin exchanges in Brazil, a number higher than that of investors on the B3 stock exchange (the new name of BM \& FBovespa) (Guimarães, 2018).

This article presents evidence that adding a small portion of Bitcoin to an investor's diversified portfolio in the Brazilian market would have increased its efficiency in the period 2013Q3-2018Q2. The present investigation is also of interest to spheres of regulation and supervision of the capital market due to the "side effect" on cost of capital. If Bitcoin becomes a popular alternative among investors, it is reasonable to assume that the cost of capital for Brazilian companies will rise, increasing the opportunity cost for those who stop investing in Bitcoin to invest in securities.

Thus, from a theoretical view, Bitcoin was expected to contribute positively to the diversification of the portfolio if its correlation with the other assets and indices of the Brazilian market was low. However, this study is relevant because it calculates and finds that that correlation is low. Besides, Bitcoin eventually has a high idiosyncratic risk that could minimize its presence on efficient portfolios. Therefore, it was not undoubting that Bitcoin would come to integrate investment alternatives with relevant weight, nor that it would cause a positive, 
statistically significant shift and an expansion of the efficient frontier of the Brazilian retail market.

Furthermore, the present study goes beyond calculating and spotting low correlation and high idiosyncratic risk to find evidence and quantifying the increased efficiency of diversified portfolios that include Bitcoin. We use several criteria to perform this quantification, such as measuring the positive shift with the efficient frontier's statistical significance, minimizing the standard deviation, and maximizing the Sharpe, Sortino, and Omega ratios.

Moreover, the article is structured as follows. In the next section, Bitcoin is presented, mainly as an investment asset. Also, we review the literature regarding the impact of Bitcoin on the efficiency of portfolios in various regions of the world and the impact of specific assets and indices on the Brazilian investor portfolio's efficiency. Section 3 presents the methodologies and data used in the investigation, while section 4 summarizes and analyzes the study results. Finally, in the last section, the conclusions of the investigation are exposed.

\section{Bitcoin Characterization and Literature Review}

\section{I Bitcoin as an Investment Asset}

On November 1, 2008, Nakamoto (2008) presented to the community of an online discussion forum his article that dealt with an electronic form of money that would allow making payments on the internet without financial institution intermediation. By eliminating intermediaries, Bitcoin would reduce transaction costs, making them cheaper. For that, he proposed a way to solve the "Byzantine Generals Problem", a question of the field of distributed computing systems. In practice, the author made it possible to overcome double-spending, based on the public and decentralized record of the moment that the transaction was carried out. The problem of double-spending, responsible for the failure of several digital currencies that emerged until then, stems from the fact that previous virtual money versions were a computer file. Thus, creating copies of the file (counterfeiting the currency) or sending the same file to different counterparties was the big issue to be resolved. And Bitcoin managed to solve it.
On January 3, 2009, Satoshi Nakamoto published the first version of the computer program related to what he wrote in his article. Bitcoin emerged.

Bitcoin allows irreversible transactions, has a maximum amount of digital currencies (21 million), and a pre-established rate of creation of new currencies, in addition to a public history of transactions. Anyone can create an account on the Bitcoin network without paying any fees, submit to the analysis and approval of a centralized entity, or even inform their identity. These rules result in a system that appears more flexible and less subject to regulatory oversight than other payment methods - although these benefits face relevant limitations linked to governance and the risks that differentiate Bitcoin from other payment methods and of store of value (Böhme, Christin, Edelman, \& Moore, 2015).

Comparing Bitcoin with other assets that could provide a low correlation with the other assets in a portfolio, one can say that Bitcoin allows the investor to hold and transport his investment, unlike the other available assets. This statement is also partially true for assets such as gold, but Bitcoin is intangible, which makes custody and transportation more easily than gold. The Bitcoin holder needs to store and transport an alphanumeric password (which he can even memorize), giving him access to his assets, in the same way that a user only needs to memorize his provider password emails to make his messages available.

Thus, from the retail investor's perspective in the Brazilian market, which lives with an environment of low economic freedom and a high level of perceived corruption, the innovation brought by Bitcoin can be of considerable value. Notice that, about 30 years ago, Brazilians were surprised by the blocking of a portion of their money deposited in a checking account and savings account, a fact that occurred not long after the former President Fernando Collor de Mello took office.

From the perspective of citizens of other countries, the recent past presents evidence that Bitcoin was used as an alternative to shield wealth in crises or as a way to make financial transactions possible in the face of the deterioration of the local sovereign currency, as we have already cited cases from Cyprus (Farrell, 2013), Greece (Rosenfeld, 2015), Argentina (Popper, 2015), India (Kashyap, 2016), China (Wildau, 2017), Zimbabwe (Urban, 2017), Venezuela (Voge, 2018) and Turkey (Cuen, 2018). 
However, there are reasons to believe that Bitcoin is taking on a commodity's characteristics and moving away from its original currency conception for transactions. For that reason, it has been increasingly called "digital gold" (James, 2018). Along these lines, Coindesk (2017, p. 80) found that there is a division of market participants concerning their understanding of Bitcoin when asked, "What do you compare Bitcoin most to?". For $57.02 \%$, the cryptoasset would be comparable to a digital currency, while $42.98 \%$ of the survey respondents considered it digital gold. In the same sense, the United States Commodity Futures Trading Commission (2015, p. 3) considers that "Bitcoin and other virtual currencies are encompassed in the definition and properly defined as commodities."

Based on data from 2013 to 2015, Hong (2017) found evidence that Bitcoin could be used as a profitable investment vehicle. He also noted that many institutional investors started investing in the cryptoasset in 2013. Also supporting Bitcoin's perspective as an investment alternative, Bouoiyour, Selmi, Tiwari, \& Olayeni (2016) found evidence that Bitcoin's price is driven by long-term fundamentals.

Dyhrberg (2016), on the other hand, used data from 2010 to 2015 to perform a volatility analysis using the GARCH model. The author concluded that Bitcoin could be classified as something between gold and the US dollar since it is neither a pure means of exchange nor a pure store of value. She also suggested that Bitcoin combines the advantages of currencies and commodities and could be useful in portfolio management.

Glaser, Zimmermann, Haferkorn, Weber, \& Siering (2014), in turn, found strong evidence that many users trade Bitcoins as a speculative investment and have little intention of using it as a mean of payment. Similarly, Yermack (2015) and Baek \& Elbeck (2015) agreed on Bitcoin's speculative investment asset's nature.

Thereby, despite discussions about Bitcoin's nature and characteristics, it is possible to note that it has gradually developed as an instrument of investment and transfer of wealth over time. It seems to have been driven, both by the increase in the legal security of cryptoassets, made possible by the growth in the jurisdictions number that have already started regulating the sector (Law Library of Congress, 2018), along with the initiative of companies to launch financial products and services related to this market.

Accordingly, in April 2014, Bloomberg (2014) included Bitcoin's price in the list of its financial information. In July 2017, the Commodity Futures Trading Commission (2017) approved the platform focusing on institutional investors LedgerX to carry out the trading, clearing, and settlement of financial derivatives with the cryptoasset as the underlying asset. In December 2017, the Chicago Board Options Exchange - CBOE (2017) and the Chicago Mercantile Exchange - CME (2017) started trading Bitcoin futures on their platforms.

Additionally, there has been a spread of Bitcoin "exchanges," which are the platforms through which most retail investors trade Bitcoins. They are similar to the home broker of securities brokers, but they have the environment for settlement and digital currency custody. They are crypto "exchanges," as they are rarely restricted to trading Bitcoins.

\subsection{Bitcoin and the Efficiency of the Investor's Portfolio}

Using data from the period 2010 to 2013, Brière et al. (2015) analyzed investment in Bitcoin from a United States investor with a diversified portfolio, both with traditional assets (worldwide stocks, bonds and hard currencies) and with alternative investments (commodities, hedge funds, and real estate). The study results show that investment portfolios with Bitcoin have a better risk-return ratio than similar portfolios without Bitcoin.

In the same vein, using data from the period 2010 to 2013, Wu \& Pandey (2014) studied Bitcoin's effect on an investment portfolio. They based the investigation on the optimization of several parameters (such as standard deviation and Sharpe, Sortino, and Omega Ratios) and the simulation of 1,000 portfolios with random weights of the constituent assets. The study showed that Bitcoin's inclusion in a portfolio during the period in question would increase its return and reduce its risk of losses. Furthermore, the investigation argues that Bitcoin has the potential to improve portfolio performance even in pessimistic scenarios.

In the same line, Gasser, Eisl, \& Weinmayer (2015) used the VaR methodology, with data from 2010 to 2015, to investigate Bitcoin's impact on the efficiency of a diversified portfolio from the perspective of a United States investor. The authors found evidence that the cryptoasset would optimize the investment portfolio since the increased risk of the portfolio from Bitcoin's inclusion would be offset by increased profitability, resulting in a better risk-return ratio. 
Aggarwal, Santosh, \& Bedi (2018) also used VaR to analyze whether Bitcoin would improve the risk-return ratio of a diversified investment portfolio in the Indian market. Based on data from 2010 to 2016, the authors found evidence that the cryptoasset would increase the portfolio's efficiency in two of the three strategies tested and that in the "long-only" strategy, the weights of the assets in the portfolio were relatively stable for different investment horizons compared to "constrained."

Using data from the period 2013 to 2015 , Hong (2017) investigated the time-series momentum in the return on investment in Bitcoin and the profitability of the trading strategy based on this analysis tool. The author concluded that adding a small portion of Bitcoin to a stock portfolio could improve performance and risk in that portfolio. It also found evidence that even institutional investors could benefit from such diversification.

Likewise, Corbet, Meegan, Larkin, Lucey, \& Yarovaya (2018) used a generalized variance decomposition technique with data from 2013 to 2017 to analyze the relationship between three cryptoassets, including Bitcoin, and traditional assets of financial markets. The authors concluded that there is a lack of relationship between cryptoassets and the traditional financial market (which shows their potential for diversification) and that cryptoassets could configure a new class of investments.

In their turn, Ciaian, Rajcaniova, \& Kancs (2016), with data from 2009 to 2015, suggested - in line with Baek \& Elbeck (2015) - that, in the long run, the price of Bitcoin would not be related to macroeconomic factors. Furthermore, they did not reject the hypothesis that speculative investor behavior affects the price of Bitcoin.

Finally, using alternative definitions of diversification by Baur \& Lucey (2010) and Ratner \& Chiu (2013), and a dynamic conditional correlation model, Bouri, Molnár, Azzi, Roubaud, \& Hagfors (2017), found evidence that Bitcoin is a good diversification asset. However, the results showed that Bitcoin is not always a great asset to protect the portfolio or refuge, and its behavior differs according to the market and the time horizon analyzed.

\subsection{Specific Assets and the Efficiency of the Brazilian Investor's Portfolio}

No academic study has been found on the impact of Bitcoin investment on the investor portfolio's efficiency in the Brazilian market. However, there are some studies on the impact of specific assets or indices on the portfolio of investors in Brazil.

Using data from 1994 to 2007, Silveira \& Barros (2010) studied the impact of agricultural commodity futures contracts on a diversified portfolio. The authors analyzed the behavior of efficient frontiers in scenarios without and with the possibility of including the tested assets, having observed expansions of the efficient frontier in some periods. However, they were not statistically significant according to the method proposed by Gibbons, Ross, \& Shanken (1989).

Oliveira \& Silva (2009) analyzed whether the investor in the Brazilian stock market would increase his portfolio's efficiency when investing in shares in other countries in Latin America. Using a combination of statistical inference techniques and stock market index data of those countries from 2003 to 2007, the authors found evidence that investing in shares in other Latin American countries could improve the efficient frontier from the Brazilian investors' perspective

In turn, Cunha \& Samanez (2014) concluded that a portfolio of shares that replicated the Corporate Sustainability Index would not have been able to outperform the Ibovespa and other sector indices of the Brazilian stock market during the analyzed period, which was 2005 to 2010 .

In another study, Caldeira et al. (2014), using the GARCH model, based on data from 2006 to 2011, found evidence with statistical significance that investment in quotas of multimarket investment funds would result in a portfolio with a better risk-return ratio than the benchmarks adopted even when the frequency of portfolio rebalancing was changed.

Finally, Lopes \& Furtado (2006) discussed the inclusion of private equity and venture capital fund quotas in the investment portfolios of private pension entities. They concluded that there are opportunities for diversification but argued that how these investments are allocated to institutional investors, especially when it comes to pension funds, cannot be based on the concepts of analysis of mean and variance, and that, given the characteristics of these assets, the asset-liability management model should be used. 


\section{Data and Methodology}

\section{I Methodology}

In order to obtain evidence of the impact of Bitcoin on the efficiency of an investment portfolio in the Brazilian market and compare the results of the present study to those found by Brière et al. (2015), and Wu \& Pandey (2014), we adopted a similar methodology to the one applied by those authors, as detailed below.

\section{I.I Efficient frontier and shift tests}

To sketch the efficient Markowitz (1952) frontier for risky assets, in each scenario (without and with Bitcoin), we fix standard deviation values (one per simulation), and the Excel Solver was used to estimate the maximum returns (together with the respective portfolios) for each level of risk. The exceptions were the point of minimum global variance, which we calculated by minimizing the standard deviation in each scenario and the point of maximum return corresponds to the point where the most profitable asset in the period and each scenario represents $100 \%$ of the portfolio.

Verifying whether the efficient frontier shift in scenarios without and with the possibility of including Bitcoin has significant statistics, we ran tests according to the methodology applied by Campbell, Lo, \& Mackinlay (1997, p. 196) based on Gibbons et al. (1989).

The test starts with the calculation of the J statistic according to the following equation (Silveira $\&$ Barros (2010):

$$
J=\left(\frac{n-i-1}{i}\right)\left(\frac{I S_{c}^{2}-I S_{s}^{2}}{1+I S_{s}^{2}}\right) \sim F(i, n-i-1)
$$

where $\mathrm{n}$ is the number of observations, $\mathrm{i}$ is the number of assets likely to be part of the diversified portfolio, and ISc and ISs are the Sharpe Ratios of portfolios with and without the possibility of including Bitcoin, respectively.

The test's logic lies in the fact that the greater the Sharpe Ratios differential in scenarios with and without the possibility of including the tested asset, the greater the likelihood that the increase in the performance indicator resulting from the inclusion of the asset it did not happen by chance. Besides, it is essential to note that the increase in the sample number positively impacts this probability. Next, based on the F distribution, the hypothesis test is carried out in which the rejection of the null hypothesis evidences the increased efficiency of the portfolio when we include Bitcoin.

Following Hardin \& Cheng (2002), to verify whether Bitcoin's inclusion results in a statistically significant improvement in the portfolio, the test was carried out for various points of the efficient frontiers. Further, align with what is suggested by Campbell et al. (1997), we applied the test to the points corresponding to the tangency portfolios in scenarios without and with the possibility of including Bitcoin.

\section{I.2 Optimization Simulations for the 5 Year Period}

We carried out iterative simulations changing the weights of assets and indices in the portfolio to identify the proportion that led to an optimal portfolio in the period 2013Q3-2018Q2 according to several criteria, such as minimizing the standard deviation and maximizing the Sharpe, Sortino, and Omega Ratios, as adopted by Wu \& Pandey (2014).

After estimating optimal portfolios without including Bitcoin, we repeated the experiment with the possibility of including Bitcoin in optimal portfolios. Thus, it was possible to verify whether the new optimal portfolios included Bitcoin and whether, for each of the criteria used, there was evidence that they are more efficient than their counterparts without Bitcoin.

We minimized the standard deviation using two approaches. First, we minimized the total standard deviation, while in the second, we minimized the risk measured based only on the negative component of the standard deviation (downside risk), which is defined as the standard deviation of returns below the minimum acceptable return, set at $0 \%$.

The Sharpe Ratio (Sharpe, 1966) measures the relationship between the risk premium (average return above the minimum acceptable return) and the risk (measured by the standard deviation), informing the amount of return expected for each unit of risk assumed.

Thus, the higher the Sharpe Ratio of the fund or portfolio (provided it is positive), the better its performance. In turn, in the Sortino Ratio (Sortino \& Price, 1994) the risk is measured based only on the negative component of the standard deviation.

The Omega Ratio, proposed by Keating \& Shadwick (2002), is based on the proportional distribution of the returns above and below the minimum acceptable 
return of reference "r." One of the main advantages of its use by the investor is that it minimizes the potential for extreme losses. The Omega Ratio is maximized by:

$\operatorname{Max}=\left[\frac{\int_{r}^{\infty}(1-F(x)) d x}{\int_{-\infty}^{r} F(x) d x}\right] \forall \begin{aligned} & \sum_{i} \omega_{p i}=1 \\ & \omega_{p i} \geq 0\end{aligned}$

where $\mathrm{F}(\mathrm{x})$ is the cumulative distribution function plotted based on the simulations performed, and $\omega_{\mathrm{pi}}$ is the weight of asset $i$ in the portfolio, the sum of the weights being equal to 1 (which represents $100 \%$ of the portfolio), and there are no negative weights (there is no "short" position).

In the optimization of the Omega Ratio, we simulated scenarios for " $\mathrm{r}$ " null and " $\mathrm{r}$ " equivalent to the adjusted average rate of daily financing calculated in the Special Settlement and Custody System for Treasury Bonds (Selic), which we used here as Risk-Free Rate.

Thus, we calculated the weights of the assets in the portfolio that optimizes them for each of the explicit criteria. We used daily returns and adopted only positive weights in the portfolios since most retail investors have only long positions. Besides, adopting such a restriction makes the article have a similar methodology - consequently making the results more easily comparable - to Wu \& Pandey (2014) and Brière, Oosterlinck, \& Szafarz (2015).

\section{I.3 Optimization Simulations for Quarterly Periods}

Finally, to verify whether Bitcoin would be included in optimized portfolios in periods of less than five years, the composition of the optimal portfolios was estimated for each of the 20 quarters of the analyzed period. The criterion adopted was the maximization of the Omega Ratio to $r=0$, and the simulations were performed based on daily returns, in line with Wu \& Pandey (2014).

\subsection{Data}

The sample period runs from $07 / 01 / 2013$, the beginning of the quarter, after which there is reliable data available for Bitcoin in the Brazilian market, until 06/30/2018. The portfolios studied were composed of the main assets and asset indexes accessible to a retail investor in the Brazilian market, and, in all cases, we used daily closing values.

Table 1

Descriptive statistics and correlations of assets and indices (daily data)

\begin{tabular}{|c|c|c|c|c|c|c|c|}
\hline & Selic & Bitcoin & IMA-Geral & Ibovespa & IFIX & Dollar & Gold \\
\hline \multicolumn{8}{|c|}{ Panel A: Descriptive statistics of assets and indices } \\
\hline Average & $0.04 \%$ & $0.50 \%$ & $0.04 \%$ & $0.05 \%$ & $0.03 \%$ & $0.05 \%$ & $0.05 \%$ \\
\hline Median & $0.04 \%$ & $0.36 \%$ & $0.05 \%$ & $0.03 \%$ & $0.05 \%$ & $0.03 \%$ & $0.00 \%$ \\
\hline Maximum & $0.05 \%$ & $41.29 \%$ & $1.96 \%$ & $6.60 \%$ & $1.75 \%$ & $8.79 \%$ & $6.94 \%$ \\
\hline Minimum & $0.02 \%$ & $-24.32 \%$ & $-3.67 \%$ & $-8.80 \%$ & $-4.86 \%$ & $-5.89 \%$ & $-4.53 \%$ \\
\hline $\begin{array}{c}\text { Standard } \\
\text { deviation } \\
\text { (daily) }\end{array}$ & $0.01 \%$ & $5.31 \%$ & $0.27 \%$ & $1.46 \%$ & $0.39 \%$ & $0.95 \%$ & $1.30 \%$ \\
\hline $\begin{array}{l}\text { Return } \\
\text { (yearly) }\end{array}$ & $11.17 \%$ & $153.86 \%$ & $11.67 \%$ & $9.03 \%$ & $8.14 \%$ & $11.58 \%$ & $11.97 \%$ \\
\hline $\begin{array}{c}\text { Standard } \\
\text { deviation } \\
\text { (yearly) }\end{array}$ & $0.14 \%$ & $83.55 \%$ & $4.20 \%$ & $23.06 \%$ & $6.11 \%$ & $14.97 \%$ & $20.45 \%$ \\
\hline $\begin{array}{l}\text { Sharpe } \\
\text { (yearly) }\end{array}$ & 0,00 & 1.71 & 0.12 & -0.09 & -0.50 & 0.03 & 0.04 \\
\hline \multicolumn{8}{|c|}{ Panel B: Correlation between the assets and indices } \\
\hline Bitcoin & -0.02 & & & & & & \\
\hline IMA-Geral & 0.06 & $-0,08^{* *}$ & & & & & \\
\hline Ibovespa & 0.01 & 0.03 & $0,45^{* *}$ & & & & \\
\hline IFIX & $0,09^{* *}$ & -0.03 & $0,29^{* *}$ & $0,26^{* *}$ & & & \\
\hline Dollar & -0.03 & 0.05 & $-0,39^{* *}$ & $-0,35^{* *}$ & $-0,28^{* *}$ & & \\
\hline Gold & -0.02 & 0.04 & $-0,36^{* *}$ & $-0,34^{* *}$ & $-0,14^{* *}$ & $0,43^{* *}$ & \\
\hline
\end{tabular}

Note: Panels based on the daily data from 2013Q3 to 2018Q2 (1239 comments). In panel B ** and * indicate statistical significance of $1 \%$ to $5 \%$, respectively. 
We used the Selic rate as a proxy for the risk-free interest rate and the IMA-Geral ${ }^{1}$ index in fixed income. Besides, we used the Ibovespa and IFIX ${ }^{2}$ indices for variable income. Furthermore, we included gold and the US dollar (Dollar) among the assets that could be part of the diversified portfolio.

The daily price and rate data of all the assets and indices came from the Economatica financial information platform. The cryptoasset data available at Economatica came from the Mercado Bitcoin, the Bitcoin "exchange" with the most extended data history in Brazil and intermediated a considerable portion of Bitcoin trades in the country the entire period under analysis.

Table 1 shows the descriptive statistics for the variables used based on daily return. Also, we presented the annual return, standard deviation, and Sharpe Ratio of assets and indices. Note that, regardless of the metric analyzed, Bitcoin disagrees with all other assets and indices. It is worth noting that the Selic standard deviation is close to zero, indicating the adequacy of its use as a Risk-Free Rate.

In terms of correlation, is clear that the correlation between Bitcoin's daily profitability and other assets is from the point of view of zero statistical significance, except the unexpectedly negative correlation with statistical significance between the cryptoasset and the IMA-General index. However, both results allow us to foresee that their inclusion in the investors' portfolios would reduce risk and contribute to its efficiency.
Bearing in mind that Bitcoin is a globally traded asset, we analyzed the existence of significant distortion between the price at which it is traded in Brazil and its price in the international market. The price of Bitcoin in the Brazilian market in proportion to the international price (in US dollars based on the Coindesk Bitcoin Price Index, converted to Real, using the daily rate of the Dollar Ptax Sale), presents a premium with an average of $6.89 \%$, median of $6.03 \%$ and standard deviation of $6.34 \%$.

\section{Presentation, Analysis, and Discussion of Results}

\section{I Efficient frontier and shift tests}

Figure 1 shows the efficient frontiers sketched without and with the possibility of including Bitcoin in the portfolios

The efficient frontier with the possibility of including Bitcoin dominates that other without the possibility of including the cryptoasset, behavior that is valid even for the points of minimum global variance (leftmost points on the curves), since they are close, but not coincide, as detailed below.

Also, the portfolios with Bitcoin reach levels of risk and return than portfolios without bitcoin do not reach. In this way, in addition to the efficient frontier shift, it is verified that it expands, being able to serve investors with a greater appetite for risk in search of greater returns. Both the shift and expansion of the efficient frontier are

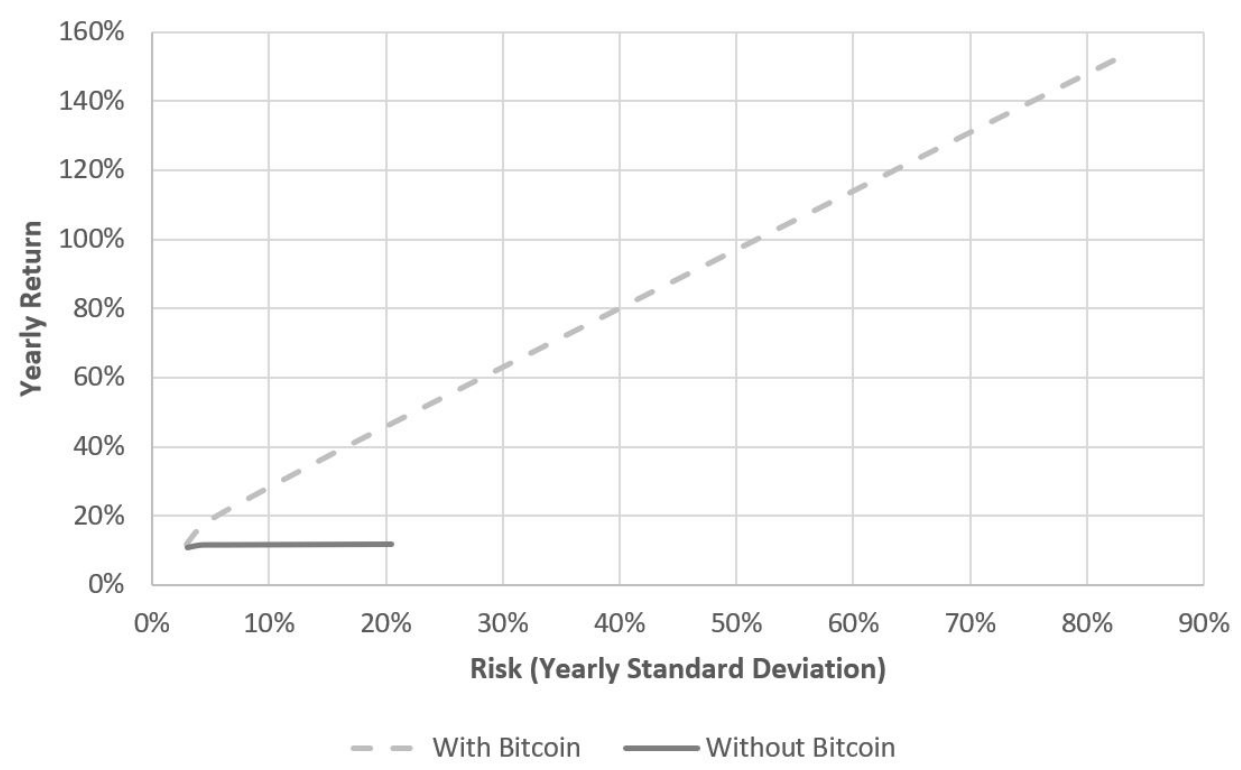

Figure 1. Efficient frontiers without and with the possibility of including Bitcoin 
evidence that Bitcoin can increase the efficiency of the Brazilian investor's diversified portfolio.

The composition of the portfolios of some points selected at the efficient frontiers is shown in Table 2.

Furthermore, it appears that the inclusion of a small portion of Bitcoin in the diversified portfolio reduced its minimum risk, albeit with a limited magnitude (from $2.98 \%$ to $2.97 \%$ ).

We also observed that at the minimum risk point of the portfolio without the possibility of including Bitcoin (2.98\%), the inclusion of Bitcoin increased the return from $10.95 \%$ to $11.80 \%$. Analyzing the points at risk of $4.20 \%, 6.11 \%$, and $14.97 \%$ (which are the risks of IMAGeral, IFIX, and Dollar, respectively), it is noted that the returns of diversified portfolios are higher than the returns of individual assets/indices. Moreover, portfolios' returns with the possibility of including Bitcoin are higher than those without it (an increase from $11.73 \%, 11.77 \%$, and $11.90 \%$ to respectively $16.74 \%, 20.99 \%$, and $37.05 \%$ ).
Finally, it is worth noting that the maximum return points correspond to a portfolio composed entirely of the highest return asset. These assets are Gold and Bitcoin in portfolios without and with the possibility of including the cruptoasset, respectively. As for the tangency portfolio, in the case where there is no possibility of including Bitcoin, it has a standard deviation of $3.27 \%$ and a return of $11.69 \%$. With the possibility of including Bitcoin, such a portfolio has a standard deviation of $18.24 \%$ and a $42.72 \%$ return.

The tangency point with Bitcoin's inclusion presents a considerably higher inclination than the scenario without the crypto. Therefore, there is an increase in the Market Risk Premium. From the investor's perspective, such an increase indicates that, with the possibility of investing in Bitcoin (and the consequent possibility of obtaining a higher return for each level of risk), he may demand a higher return on the other investment products available on the market. From the companies' perspective, this

Table 2

\section{Points selected from efficient frontiers}

\begin{tabular}{|c|c|c|c|c|c|c|c|c|}
\hline & \multirow{2}{*}{$\begin{array}{l}\text { Standard } \\
\text { Deviation }\end{array}$} & \multirow{2}{*}{ Return } & \multicolumn{6}{|c|}{ Portfolio composition } \\
\hline & & & Bitcoin & IMA-Geral & Ibovespa & IFIX & Dollar & Gold \\
\hline \multirow{5}{*}{$\begin{array}{c}\text { Without } \\
\text { BTC }\end{array}$} & $2.98 \%$ & $10.95 \%$ & & $64.38 \%$ & $0.00 \%$ & $20.49 \%$ & $10.82 \%$ & $4.31 \%$ \\
\hline & $4.20 \%$ & $11.73 \%$ & & $80.61 \%$ & $0.00 \%$ & $0.00 \%$ & $0.00 \%$ & $19.39 \%$ \\
\hline & $6.11 \%$ & $11.77 \%$ & & $68.16 \%$ & $0.00 \%$ & $0.00 \%$ & $0.00 \%$ & $31.84 \%$ \\
\hline & $14.97 \%$ & $11.90 \%$ & & $25.11 \%$ & $0.00 \%$ & $0.00 \%$ & $0.00 \%$ & $74.89 \%$ \\
\hline & $20.45 \%$ & $11.97 \%$ & & $0.00 \%$ & $0.00 \%$ & $0.00 \%$ & $0.00 \%$ & $100.00 \%$ \\
\hline \multirow[t]{12}{*}{ With BTC } & $2.97 \%$ & $11.36 \%$ & $0.29 \%$ & $64.37 \%$ & $0.00 \%$ & $20.36 \%$ & $10.72 \%$ & $4.27 \%$ \\
\hline & $2.98 \%$ & $11.80 \%$ & $0.56 \%$ & $65.50 \%$ & $0.00 \%$ & $19.04 \%$ & $10.60 \%$ & $4.30 \%$ \\
\hline & $4.20 \%$ & $16.74 \%$ & $3.66 \%$ & $78.41 \%$ & $0.00 \%$ & $3.92 \%$ & $9.32 \%$ & $4.69 \%$ \\
\hline & $6.11 \%$ & $20.99 \%$ & $6.54 \%$ & $80.74 \%$ & $0.00 \%$ & $0.00 \%$ & $8.13 \%$ & $4.59 \%$ \\
\hline & $14.97 \%$ & $37.05 \%$ & $17.84 \%$ & $75.21 \%$ & $0.00 \%$ & $0.00 \%$ & $3.47 \%$ & $3.48 \%$ \\
\hline & $20.45 \%$ & $46.53 \%$ & $24.51 \%$ & $71.94 \%$ & $0.00 \%$ & $0.00 \%$ & $0.71 \%$ & $2.83 \%$ \\
\hline & $30.00 \%$ & $62.92 \%$ & $36.04 \%$ & $63.91 \%$ & $0.00 \%$ & $0.00 \%$ & $0.00 \%$ & $0.05 \%$ \\
\hline & $40.00 \%$ & $79.97 \%$ & $48.03 \%$ & $51.97 \%$ & $0.00 \%$ & $0.00 \%$ & $0.00 \%$ & $0.00 \%$ \\
\hline & $50.00 \%$ & $96.98 \%$ & $60.00 \%$ & $40.00 \%$ & $0.00 \%$ & $0.00 \%$ & $0.00 \%$ & $0.00 \%$ \\
\hline & $60.00 \%$ & $113.97 \%$ & $71.94 \%$ & $28.06 \%$ & $0.00 \%$ & $0.00 \%$ & $0.00 \%$ & $0.00 \%$ \\
\hline & $70.00 \%$ & $130.94 \%$ & $83.88 \%$ & $16.12 \%$ & $0.00 \%$ & $0.00 \%$ & $0.00 \%$ & $0.00 \%$ \\
\hline & $83.52 \%$ & $153.86 \%$ & $100.00 \%$ & $0.00 \%$ & $0.00 \%$ & $0.00 \%$ & $0.00 \%$ & $0.00 \%$ \\
\hline
\end{tabular}

Note: The table shows the composition of the portfolios of some selected points in the efficient frontiers presented in the previous figure. We fixed several standard deviation values (one per simulation) to sketch the efficient frontier for risky assets in each scenario (without and with Bitcoin), and we used the Excel Solver supplement to estimate maximum returns (together) with the respective portfolios) for each level of risk. The exceptions were the minimum point of global variance in each scenario, which was calculated by minimizing the standard deviation, and the maximum return point, which simply corresponds to the point at which the most profitable asset in the period in each scenario represents $100 \%$ of the portfolio. 
increase in the Market Risk Premium indicates a potential increase in their cost of capital. The increased return on the Market Portfolio and the Market Risk Premium are evidence that Bitcoin can increase the efficiency of a diversified portfolio within reach of retail investors in the Brazilian market.

To check the statistical significance of the efficient frontier shift, as Silveira \& Barros (2010), we selected 4 points based on the standard deviation of individual assets (IMA General IFIX, Dollar, and Gold). Moreover, we repeated the statistical significance test using the tangent portfolios in scenarios with and without the possibility of inclusion of Bitcoin.

Table 3 shows the Sharpe Ratio results and the number of observations in the series monthly.

Analyzing the results, Panel A shows that, when sufficiently removed from the portfolios of minimum global variance, it appears that the shift of the efficient frontier has statistical significance at a level of $10 \%$. Similarly, in Panel B, it appears that the shift of the tangency portfolios again has statistical significance at a level of $10 \%$.

Therefore, we can say that there is a statistically significant shift of the efficient frontier when we included Bitcoin in the Brazilian market, which shows the cryptoasset's ability to increase the efficiency of the retail investor's portfolio.

\subsection{Optimization Simulations for the 5 Year Period}

In this stage, we verified whether Bitcoin could optimize the performance of a diversified portfolio in the Brazilian market according to different criteria. Thus, we estimated the optimal portfolios without and with the possibility of including Bitcoin for each of the investigated criteria, with the respective indicators (see Table 4).

The first two columns of panels show the estimation results of the portfolios to minimize the risk measured by the volatility of returns. It is noteworthy that the optimal portfolios are composed mainly by the IMA-Geral, followed by relevant participation of IFIX, Dollar, and Gold, regardless of the use of the total standard deviation (Total SD) or only its negative component (Semi-SD), and regardless of the possibility of including Bitcoin in the portfolio.

In the scenario where there is the possibility of including Bitcoin, the optimal portfolios now have a small portion of the cryptoasset $(0.29 \%$ and $0.52 \%$ Bitcoin in the portfolios that minimize the Total SD and Semi-SD, respectively), which results in a reduction (albeit marginal) of portfolio risk (Total SD reduced from $2.98 \%$ to $2.97 \%$ and Semi-SD reduced from $2.14 \%$ to $2.13 \%$ ).

The two central columns of the panels show the compositions of the portfolios that maximize the

Table 3

\section{Calculation of statistical significance}

\begin{tabular}{|c|c|c|c|c|c|c|c|c|}
\hline $\begin{array}{l}\text { Standard } \\
\text { Deviation }\end{array}$ & \multicolumn{2}{|c|}{ Return (a.a.) } & \multicolumn{2}{|c|}{ Sharpe Ratio (a.a.) } & \multicolumn{2}{|c|}{ Sharpe Ratio (a.m.) } & Statistic J & Significance \\
\hline \multicolumn{9}{|c|}{ Panel A: Calculation of statistical significance based on selected points } \\
\hline & $\begin{array}{c}\text { Without } \\
\text { BTC }\end{array}$ & With BTC & $\begin{array}{c}\text { Without } \\
\text { BTC }\end{array}$ & With BTC & $\begin{array}{c}\text { Without } \\
\text { BTC }\end{array}$ & With BTC & & \\
\hline $4.20 \%$ & $11.73 \%$ & $16.74 \%$ & 0.1336 & 1.3273 & 0.0386 & 0.3831 & 1.2817 & 0.2816 \\
\hline $6.11 \%$ & $11.77 \%$ & $20.99 \%$ & 0.0978 & 1.6065 & 0.0282 & 0.4638 & 1.8913 & $0,0995^{*}$ \\
\hline $14.97 \%$ & $11.90 \%$ & $37.05 \%$ & 0.0485 & 1.7281 & 0.0140 & 0.4988 & 2.1960 & $0,0577^{*}$ \\
\hline $20.45 \%$ & $11.97 \%$ & $46.53 \%$ & 0.0391 & 1.7291 & 0.0113 & 0.4991 & 2.1993 & $0,0574^{*}$ \\
\hline \multicolumn{9}{|c|}{ Panel B: Calculation of statistical significance based on tangency portfolios } \\
\hline & $\begin{array}{c}\text { Without } \\
\text { BTC }\end{array}$ & With BTC & & & & & & \\
\hline $3.27 \%$ & $11.69 \%$ & & \multicolumn{2}{|c|}{0.1585} & \multicolumn{2}{|c|}{0.0458} & 2.1791 & $0,0595^{*}$ \\
\hline $18.24 \%$ & & $42.72 \%$ & \multicolumn{2}{|c|}{1.7296} & \multicolumn{2}{|c|}{0.4993} & & \\
\hline
\end{tabular}

Note: Number of observations of the series in both panels $(n)=60$ months. Number of portfolio assets in both panels (i) $=6 .{ }^{* * *},{ }^{* *} \mathrm{e}$

* indicate statistical significance of $1 \%, 5 \%$ and $10 \%$, respectively, in both panels. 


\section{Optimal portfolios without and with the possibility of including Bitcoin}

\begin{tabular}{|c|c|c|c|c|c|c|}
\hline & $\begin{array}{c}\text { Minimal Risk } \\
\text { (Total SD) }\end{array}$ & $\begin{array}{l}\text { Minimal Risk } \\
\quad \text { (Semi-SD) }\end{array}$ & $\begin{array}{c}\text { Sharpe } \\
\text { Maximum }\end{array}$ & $\begin{array}{c}\text { Sortino } \\
\text { Maximum }\end{array}$ & $\begin{array}{c}\text { Omega } \\
\text { Maximum [0\%] }\end{array}$ & $\begin{array}{c}\text { Omega } \\
\text { Maximum } \\
{[100 \% \text { Selic }]}\end{array}$ \\
\hline \multicolumn{7}{|c|}{ Panel A: Optimal portfolios without Bitcoin } \\
\hline IMA-Geral & $64.38 \%$ & $66.24 \%$ & $84.00 \%$ & $79.59 \%$ & $75.57 \%$ & $66.21 \%$ \\
\hline Ibovespa & $0.00 \%$ & $0.00 \%$ & $0.00 \%$ & $0.00 \%$ & $0.00 \%$ & $4.29 \%$ \\
\hline IFIX & $20.49 \%$ & $14.08 \%$ & $0.00 \%$ & $0.00 \%$ & $10.73 \%$ & $0.00 \%$ \\
\hline Dollar & $10.82 \%$ & $12.40 \%$ & $8.61 \%$ & $11.07 \%$ & $10.58 \%$ & $20.61 \%$ \\
\hline Gold & $4.31 \%$ & $7.29 \%$ & $7.39 \%$ & $9.34 \%$ & $3.12 \%$ & $8.90 \%$ \\
\hline Return & $10.95 \%$ & $11.19 \%$ & $11.69 \%$ & $11.69 \%$ & $11.29 \%$ & $11.57 \%$ \\
\hline $\begin{array}{l}\text { Standard } \\
\text { Deviation }\end{array}$ & $2.98 \%$ & $3.11 \%$ & $3.27 \%$ & $3.38 \%$ & $3.07 \%$ & $3.89 \%$ \\
\hline Index & $2.98 \%$ & $2.14 \%$ & 0.16 & 0.23 & 1.89 & 1.05 \\
\hline $\mathbf{P}[$ loss $]$ & $37.32 \%$ & $38.37 \%$ & $38.85 \%$ & $39.90 \%$ & $36.91 \%$ & $48.63 \%$ \\
\hline \multicolumn{7}{|c|}{ Panel B: Optimal portfolios with Bitcoin } \\
\hline Bitcoin & $0.29 \%$ & $0.52 \%$ & $21.83 \%$ & $16.24 \%$ & $1.43 \%$ & $29.34 \%$ \\
\hline IMA-Geral & $64.37 \%$ & $65.17 \%$ & $73.26 \%$ & $82.70 \%$ & $73.71 \%$ & $65.48 \%$ \\
\hline Ibovespa & $0.00 \%$ & $0.00 \%$ & $0.00 \%$ & $0.00 \%$ & $0.00 \%$ & $0.00 \%$ \\
\hline IFIX & $20.36 \%$ & $15.48 \%$ & $0.00 \%$ & $0.00 \%$ & $11.36 \%$ & $0.00 \%$ \\
\hline Dollar & $10.72 \%$ & $12.89 \%$ & $1.82 \%$ & $0.03 \%$ & $9.89 \%$ & $5.17 \%$ \\
\hline Gold & $4.27 \%$ & $5.94 \%$ & $3.10 \%$ & $1.02 \%$ & $3.61 \%$ & $0.00 \%$ \\
\hline Return & $11.36 \%$ & $11.87 \%$ & $42.72 \%$ & $34.77 \%$ & $13.31 \%$ & $53.39 \%$ \\
\hline $\begin{array}{l}\text { Standard } \\
\text { Deviation }\end{array}$ & $2.97 \%$ & $3.06 \%$ & $18.24 \%$ & $13.72 \%$ & $3.18 \%$ & $24.46 \%$ \\
\hline Index & $2.97 \%$ & $2.13 \%$ & 1.73 & 2.41 & 1.98 & 1.32 \\
\hline P [loss] & $36.75 \%$ & $37.32 \%$ & $41.76 \%$ & $41.36 \%$ & $36.67 \%$ & $44.83 \%$ \\
\hline
\end{tabular}

Note: The Optimized Performance Indicator in each of the 6 columns was, respectively: Total Standard Deviation, Semi-DS (Downside risk), Sharpe Ratio, Sortino Ratio, and in the 2 last columns, Omega Ratio. "P [loss]" is the probability of loss defined as the number of days on which there was a negative return or less than the average Selic for the period (according to the reference " $r$ ") in relation to the total number of days analyzed.

Sharpe and Sortino Ratios. The addition of Bitcoin to the diversified portfolio has optimized these indicators in a very relevant way.

With the inclusion of $21.83 \%$ of Bitcoin in the portfolio, the maximum Sharpe Ratio increased from 0.16 to 1.73 . As we saw earlier, these are (theoretically) the Market Portfolios (that is, the tangency portfolios) in scenarios without and with the possibility of including Bitcoin. Regarding the maximization of the Sortino Ratio, the addition of $16.24 \%$ of Bitcoin in the diversified portfolio caused the indicator to increase from 0.23 to 2.41 .

Finally, the last two columns of the panels present the portfolio compositions that maximize the Omega Ratio in two scenarios. The first considers a minimum acceptable return of reference $r=0$, as adopted by Wu \& Pandey (2014), while the second considers an "r" equivalent to the average Selic rate of the analyzed period. For $r=0$, IMA-Geral represented more than $70 \%$ of the portfolio in both scenarios (without and with the possibility of including Bitcoin), followed by IFIX, Dollar, and Gold. It turns out that by maximizing the Omega Ratio, the inclusion of $1.43 \%$ Bitcoin increased it from 1.89 to 1.98 , while the likelihood of loss was reduced from $36.91 \%$ to $36.67 \%$.

The loss probability is defined as the number of days when there was a negative return or less than the 


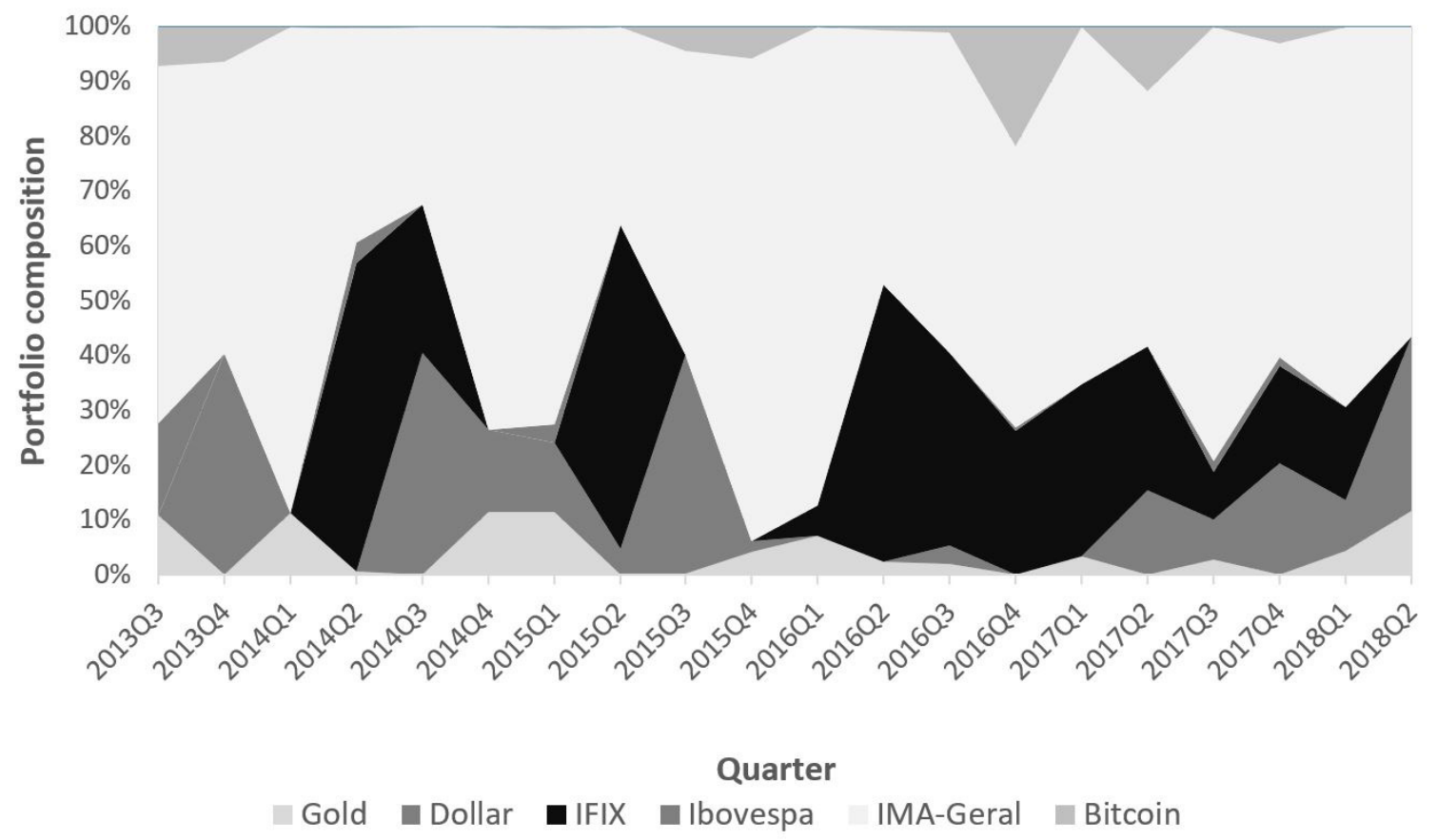

Figure 2. Maximum Omega portfolios for $r=0$ (daily data)

average of the Selic period (as " $\mathrm{r}$ " of reference) for the total number of days analyzed.

Furthermore, it is noted that, by maximizing Omega, the probability of loss of the optimized portfolios is minimized when compared to the portfolios estimated by the other criteria (minimization of Total SD and Semi-SD and maximization of Sharpe and Sortino Ratios) in both scenarios (without and with Bitcoin). For example, for the Bitcoin scenario, Omega optimization results in a loss probability of $36.67 \%$, while that value is $36.75 \%, 37.32 \%, 41.76 \%$, and $41.36 \%$ in the other criteria.

Additionally, we estimated the optimal portfolios for a scenario in which " $r$ " is equivalent to the average Selic rate for the period. When there is no possibility of including Bitcoin, the largest portion of the portfolio is still composed of IMA-Geral, followed by Dollar, Gold, and Ibovespa. When there is the possibility of including Bitcoin, the supremacy of the IMA-Geral is balanced with a $29.34 \%$ share of the crypto. Bitcoin's presence in the portfolio caused the maximum Omega Ratio to increase from 1.05 to 1.32. The likelihood of loss, in turn, was reduced from $48.63 \%$ to $44.83 \%$.

Finally, it is important to mention that the improvement of the various indicators treated in this section caused by Bitcoin's inclusion is evidence that it can increase the efficiency of a diversified portfolio in the Brazilian market.

\subsection{Optimization Simulations for Quarterly Periods}

In this stage of the investigation, we estimated the optimal portfolios in each quarter with the possibility of including Bitcoin according to the Omega Ratio maximization criterion. We based this study on the daily return on assets and indices, and we used $\mathrm{r}=0$ in line with what was done by Wu \& Pandey (2014). Figure 2 shows the optimal quarterly portfolios.

We observed that Bitcoin is included in the optimal portfolio in several periods, specifically in the second semesters of 2013, 2015, and 2016 and in the second and fourth quarters of 2017.

It is interesting to mention that the portfolio optimized by quarterly intervals presents a better balance between the various assets and component indices than the estimated portfolio for the entire 5 -year period. In this sense, the supremacy of IMAGeral was reduced from $73.71 \%$ in the entire period to a quarterly average of $61.08 \%$, while the other assets and indexes had their average participation increased in simulations by quarterly intervals. The order of participation of each asset or index in the diversified portfolio is not changed, whether the optimization is 
done for the entire period or at quarterly intervals. The decreasing order of assets/indexes' participation in the diversified portfolios was: IMA-Geral, IFIX, Dollar, Gold, Bitcoin, and Ibovespa ${ }^{3}$.

Furthermore, the optimization based on shorter periods made it possible to increase the Omega from 1.98 (see Table 4) to an average of 4.18. Bitcoin, which obtained a $1.43 \%$ share in the estimated portfolio for the entire period, reached an average of $3.14 \%$ in quarterly portfolios.

The results presented in this section show that Bitcoin can increase the performance of an investment portfolio over long periods ( 5 years) and in short periods (quarterly basis).

\section{Conclusions}

In line with the results achieved by Wu \& Pandey (2014) and Brière et al. (2015) concerning the United States market, for the period from 2010 to 2013, there is evidence that Bitcoin would have been able to increase the efficiency of the diversified investment portfolio of a retail investor in the Brazilian market from 2013Q3 to 2018 Q2.

The primary evidence in this regard refers to the positive shift of the efficient frontier when there is the participation of the cryptoasset in the portfolio in relation to the scenario without it. This displacement has statistical significance and is in line with the results found by Brière et al. (2015). Furthermore, in addition to the positive shift, there was an expansion of the efficient frontier with Bitcoin's inclusion.

The positive shift of the efficient frontier in the Bitcoin scenario resulted in a significant increase in the return of the tangency portfolio and the market risk premium, which is also evidence of the cryptoasset's ability to increase the efficiency of the portfolio.

Similarly, simulations of optimal portfolios without and with the possibility of including Bitcoin showed that the addition of a portion of Bitcoin, albeit small in some cases, improved all the indicators that we wanted to optimize, such as the standard deviation and the Sharpe, Sortino and Omega Ratios. Into the bargain, quarterly interval optimization indicated that Bitcoin made up the optimal portfolio in several quarters, increasing the benchmark Omega Ratio. These results are also evidence of Bitcoin's potential to increase the investment portfolio's efficiency and are in line with Wu \& Pandey (2014).

Given the evidence of changes in the tangency portfolio and the increase in the market risk premium, it is reasonable to assume that the cost of capital of Brazilian companies may increase if the adhesion to investment in the cryptoasset continues to grow and it maintains a good performance as the one observed in recent years, constituting a new challenge for the development of the capital market in Brazil. Thus, this scenario may deserve attention from public entities such as the CVM and the Brazilian Development Bank.

\section{Notes}

i. IMA-General is an index developed by the Brazilian Financial and Capital Markets Association (ANBIMA) and consists of a family of fixed incomes representing the public debt through the market prices of a portfolio of federal government bonds.

ii. IFIX is the average performance index of the prices of real estate funds traded on B3's stock exchange and over-the-counter markets.

iii. The optimal portfolios simulated throughout the study do not include the Ibovespa, except for small shares in the optimal portfolio that maximizes the Omega to " $\mathrm{r}$ " equivalent to the average Selic rate of the period in the scenario without Bitcoin and in some quarters in the last part of the investigation. This is due to its reduced performance in terms of the risk-return binomial in the analyzed period. In fact, Ibovespa presented the second lowest return (losing only to IFIX) and the second highest risk (losing only to Bitcoin) in the period, which is therefore far from the efficient frontier.

\section{References}

Aggarwal, S., Santosh, M., \& Bedi, P. (2018). Bitcoin and portfolio diversification: Evidence from India. In Kar A., Sinha S., \& Gupta M. (Eds.), Digital India. Advances in theory and practice of emerging markets (pp. 99-115). doi:10.1007/978-3-319-78378-9_6 
Baek, C., \& Elbeck, M. (2015). Bitcoins as an investment or speculative vehicle? A first look. Applied Economics Letters, 22(1), 30-34.

Baur, D. G., \& Lucey, B. M. (2010). Is gold a hedge or a safe haven? An analysis of stocks, bonds and gold. Financial Review, 45(2), 217-229.

Bloomberg. (2014). Bitcoin now on Bloomberg. Available in https://www.bloomberg.com/company/announcements/ bitcoin-now-bloomberg/

Böhme, R., Christin, N., Edelman, B., \& Moore, T. (2015). Bitcoin Economics, technology, and governance. Journal of Economic Perspectives, 29(2), 213-238.

Bouoiyour, J., Selmi, R., Tiwari, A. K., \& Olayeni, O. R. (2016). What drives Bitcoin price? Economics Bulletin, 36(2), 843-850.

Bouri, E., Molnár, P., Azzi, G., Roubaud, D., \& Hagfors, L. I. (2017). On the hedge and safe haven properties of Bitcoin Is it really more than a diversifier? Finance Research Letters, 20, 192-198.

Brière, M., Oosterlinck, K., \& Szafarz, A. (2015). Virtual currency, tangible return: Portfolio diversification with bitcoin. Journal of Asset Management, 16(6), 365-373.

Caldeira, J. F., Moura, G. V., Santos, A. A. P., \& Tessari, C. (2014). Seleção de carteiras com modelos fatoriais heterocedásticos: Aplicação para fundos de fundos multimercados. Revista de Administração Mackenzie, 15(2), 127-161.

Campbell, J. Y., Lo, A. W., \& Mackinlay, A. C. (1997). The econometrics of financial markets. Princeton, New Jersey: Princeton University Press.

Chicago Board Options Exchange - Cboe. (2017). Cboe Bitcoin futures (XBT) close first day of trading. Available in http://ir.cboe.com/ /media/Files/C/CBOE-IR-V2/ press-release/2017/cboe-bitcoin-futures-end-first-daywith-volume-of-more-than-4000.pdf

Chicago Mercantile Exchange - CME. (2017). CME Bitcoin futures - Frequently asked questions. Available in https://www.cmegroup.com/education/bitcoin/cmebitcoin-futures-frequently-asked-questions.html
Ciaian, P., Rajcaniova, M., \& Kancs, D. (2016). The economics of Bitcoin price formation. Applied Economics, 48(19), 1799-1815.

Coindesk. (2017). State of Blockchain Q2 2017. Available in https://media.coindesk.com/uploads/2017/09/ state_of_blockchain_q2_2017.pdf

CoinMarketCap. (2018). 24 hour volume rankings (exchange). Available in https://coinmarketcap.com/ exchanges/volume/24-hour/all/

Commodity Futures Trading Commission. (2015). CFTC Docket No. 15-29. Available in http://www.cftc.gov/ idc/groups/public/@lrenforcementactions/documents/ legalpleading/enfcoinfliprorder09172015.pdf

Commodity Futures Trading Commission. (2017). Press Release 7584-17. Available in https://www.cftc.gov/ PressRoom/PressReleases/pr7584-17

Corbet, S., Meegan, A., Larkin, C., Lucey, B., \& Yarovaya, L. (2018). Exploring the dynamic relationships between cryptocurrencies and other financial assets. Economics Letters, 165, 28-34.

Cuen, L. (2018). Volumes surge on Turkey's crypto exchanges as lira tanks. Coindesk. Available in https:// www.coindesk.com/turkey-crypto-exchanges-bitcoin-lira/

Cunha, F. A. F. S., \& Samanez, C. P. (2014). Análise de desempenho dos investimentos sustentáveis no mercado acionário brasileiro. Production, 24(2), 420-434.

Dyhrberg, A. H. (2016). Bitcoin, gold and the dollar A GARCH volatility analysis. Finance Research Letters, 16, 85-92.

ExchangeWar. (2018). Página principal. Available in https://exchangewar.info/

Farrell, M. (2013). Bitcoin prices surge post-Cyprus bailout. CNN Money. Available in https://money.cnn. com/2013/03/28/investing/bitcoin-cyprus/index.html

Gasser, S., Eisl, A., \& Weinmayer, K. (2015). Caveat emptor: Does Bitcoin improve portfolio diversification? Available in https://epub.wu.ac.at/4674/1/SSRN-id2408997.pdf 
Gibbons, M. R., Ross, S. A., \& Shanken, J. (1989). Test of the efficiency of a given portfolio. Econometrica, 57(5), 279-295.

Glaser, F., Zimmermann, K., Haferkorn, M., Weber, M., \& Siering, M. (2014). Bitcoin - asset or currency? Revealing users' hidden intentions. Paper presented at the European Conference on Information Systems, Tel Aviv.

Guimarães, F. (2018). Investidor em bitcoin se aproxima do total do Tesouro Direto. Exame. Available in https:// exame.abril.com.br/seu-dinheiro/investidor-em-bitcoinse-aproxima-do-total-do-tesouro-direto/

Hardin, W. G., \& Cheng, P. (2002). Farmland investment under conditions of certainty and uncertainty. Journal of Real Estate Finance and Economics, 25(1), 81-98

Heritage Foundation. (2018). 2018 index of economic freedom. Available in https://www.heritage.org/index/ pdf/2018/book/highlights.pdf

Hong, K. H. (2017). Bitcoin as an alternative investment vehicle. Information Technology and Management, 18(4), 265-275.

James, H. (2018). Lucre's allure. Finance and Development - A Quarterly Publication of the International Monetary Fund, 55(2), 17-19.

Kashyap, K. (2016). India’s demonetization is causing Bitcoin to surge inside the country. Forbes. Available in https://www.forbes.com/sites/krnkashyap/2016/12/22/ indias-demonetization-is-causing-bitcoin-to-surge-insidethe-country/\#2b6b15757dfc

Keating, C., \& Shadwick, W. F. (2002). A universal performance measure. Journal of Performance Measurement, 6(3), 59-85. Available in https://www.researchgate.net/ publication/228550687_A_Universal_Performance_ Measure

Law Library of Congress. (2018). Regulation of cryptocurrency around the world. Available in https://www.loc.gov/law/ help/cryptocurrency/regulation-of-cryptocurrency.pdf

Lopes, A. B., \& Furtado, C. V. (2006). Private equity na carteira de investimentos das entidades de previdência privada. Revista Contabilidade \& Finanças, 17(n.spe2), 108-126.
Markowitz, H. (1952). Portfolio selection. Journal of Finance, 7(1), 77-91.

Nakamoto, S. (2008). Bitcoin A peer-to-peer electronic cash system. Bitcoin.org. Available in https://bitcoin.org/ bitcoin.pdf

Oliveira, M. A. C., \& Silva, L. S. A. (2009). A inclusão de açôes da América Latina sob o ponto de vista do investidor brasileiro: Inferências sobre os pesos na fronteira eficiente. Gestão \& Produção, 16(2), 325-332

Organisation for Economic Cooperation and Development. (2015). Results from PISA 2015 - Financial literacy - Country note - Brazil. Available in https://www.oecd.org/pisa/ PISA-2105-Financial-Literacy-Brazil.pdf

Popper, N. (2015). Can Bitcoin conquer Argentina? New York Times. Available in https://www.nytimes. com/2015/05/03/magazine/how-bitcoin-is-disruptingargentinas-economy.html

Ratner, M., \& Chiu, C. C. (2013). Hedging stock sector risk with credit default swaps. International Review of Financial Analysis, 30, 18-25

Rosenfeld, E. (2015). Greek crisis stokes Bitcoin prices higher. CNBC. Available in https://www.cnbc.com/2015/06/29/ greek-crisis-stokes-bitcoin-prices-higher.html

Sharpe, W. F. (1966). Mutual fund performance. Journal of Business, 39(1), 119-138.

Silveira, R. L. F., \& Barros, G. S. A. C. (2010). Uma análise da alocaçáo de contratos futuros sobre commodities em portfólios diversificados. Revista de Economia e Sociologia Rural, 48(1), 195-222.

Sortino, F. A., \& Price, L. N. (1994). Performance measurement in a downside risk framework. Journal of Investing, 3(3), 59-64.

Urban, R. (2017). Bitcoin is the new crisis currency. Bloomberg. Available in https://www.bloomberg.com/ news/articles/2017-11-17/bitcoin-emerges-as-crisiscurrency-in-hotspots-such-as-zimbabwe

Viglione, R. (2015). Does governance have a role in pricing? Cross-country evidence from Bitcoin markets. Available in https://ssrn.com/abstract=2666243 
Voge, C. (2018). Where could Bitcoin succeed as a currency? In a failed state. Wired. Available in https://www.wired.com/story/ where-could-bitcoin-succeed-as-a-currency-in-a-failed-state/

Wildau, G. (2017). China probes Bitcoin exchanges amid capital flight fears. Financial Times. Available in https://www. ft.com/content/bad16a88-d6fd-11e6-944b-e7eb37a6aa8e
Wu, C. Y., \& Pandey, V. K. (2014). The value of Bitcoin in enhancing the efficiency of an investor's portfolio. Journal of Financial Planning, 27(9), 44-52.

Yermack, D. (2015). Is Bitcoin a real currency? An economic appraisal. Handbook of Digital Currency, 31-43. 


\section{Financial support:}

CEF.UP: This research is financed by European Union and Portuguese public funds through the FCT (Fundação para a Ciência e a Tecnologia, I.P.) and the European Social Funds (Operational Program Norte 2020) under project number UIDB/04105/2020.

\section{Conflicts of interest:}

The authors have no conflict of interest to declare.

\section{Copyrights:}

RBGN owns the copyrights of this published content.

\section{Plagiarism analysis:}

RBGN performs plagiarism analysis on all its articles at the time of submission and after approval of the manuscript using the iThenticate tool.

\section{Authors:}

1. Davi Trindade Batista, Master in Economics and Business Administration, University of Porto, Faculty of Economics, Porto, Portugal.

E-mail: dbatista@cvm.gov.br

2. Carlos Francisco Ferreira Alves, PhD in Economics, University of Porto, Faculty of Economics, Porto, Portugal. E-mail: calves@fep.up.pt

\section{Authors' Contributions:}

Davi Trindade Batista: Definition of research problem; Development of hypotheses or research questions (empirical studies); Development of theoretical propositions (theoretical work); Definition of methodological procedures; Data Collection; Literature review; Statistical analysis; Analysis and interpretation of data; Critical revision of the manuscript; Manuscript writing.

Carlos Francisco Ferreira Alves: Definition of research problem; Development of hypotheses or research questions (empirical studies); Development of theoretical propositions (theoretical work); Definition of methodological procedures; Data Collection; Literature review; Statistical analysis; Analysis and interpretation of data; Critical revision of the manuscript; Manuscript writing. 